\title{
Linkage disequilibrium in inbred North African families allows fine genetic and physical mapping of triple A syndrome
}

\author{
Smaill Hadj-Rabia ${ }^{1}$, Rémi Salomon ${ }^{1}$, Anna Pelet ${ }^{1}$, Clothilde Penet $^{1}$, Annick Rotschild ${ }^{1}$, \\ Marc-Henri de Laët ${ }^{2}$, Beji Chaouachi ${ }^{3}$, Ratiba Hannachi ${ }^{4}$, Fawzi Bakiri ${ }^{4}$, Raja Brauner ${ }^{5}$, \\ Jean-Louis Chaussain ${ }^{6}$, Arnold Munnich ${ }^{1}$ and Stanislas Lyonnet ${ }^{1}$
}

\begin{abstract}
${ }^{1}$ Département de Génétique et Unité de Recherches sur les Handicaps Génétiques de I'Enfant, Inserm U-393, Hôpital Necker-Enfants M alades, Paris, France; ${ }^{2}$ Service de Chirurgie Pédiatrique, Hôpital d'Enfants, Brussels, Belgium; ${ }^{3}$ Service de Chirurgie Pédiatrique B, Hôpital d'Enfants de Tunis, Tunisia; ${ }^{4}$ Service d'Endocrinologie, Hôpital de Bologhine, Algiers, Algeria; ${ }^{5}$ Service d'Endocrinologie Pédiatrique, Hôpital Necker-Enfants Malades, Paris; ${ }^{6}$ Service d'Endocrinologie Pédiatrique, Hôpital Saint-Vincent-de-Paul, Paris, France
\end{abstract}

Triple A syndrome (Allgrove syndrome, MIM No. 231550) is a rare autosomal recessive disorder characterised by ACTH-resistant adrenal insufficiency, achalasia of the cardia, and alacrimia. The triple A gene has been previously mapped to chromosome 12q13 in a maximum interval of $6 \mathrm{cM}$ between loci D12S1629 and D12S312. Using linkage analysis in 12 triple A families, mostly originating from North Africa, we confirm that the disease locus maps to the $12 q 13$ region $\left(Z_{\max }=10.89\right.$ at $\Theta=0$ for $\left.D 12 S 1604\right)$ and suggest that triple $A$ is a genetically homogeneous disorder. Recombination events as well as homozygosity for polymorphic markers enabled us to reduce the genetic interval to a $3.9 \mathrm{cM}$ region. Moreover, total linkage disequilibrium was found at the D12S1604 locus between a rare allele and the mutant chromosomes in North African patients. Analysis of markers at five contiguous loci showed that most of the triple A chromosomes are derived from a single founder chromosome. As all markers are located in a $0 \mathrm{cM}$ genetic interval and only allele 5 at the D12S1604 locus was conserved in mutant chromosomes, we speculate that the triple A mutation is due to an ancient Arabian founder effect that occurred before migration to North Africa. Since we also found linkage disequilibrium at D12S1604 in two patients from Southern Europe (France and Spain), the founder effect might well extend to other Mediterranean countries. Taking advantage of a YAC contig encompassing the triple A minimal physical region, the triple $A$ gene was mapped to a $1.7 \mathrm{Mb}$ DNA fragment accessible to gene cloning. European Journal of Human Genetics (2000) 8, 613-620.

Keywords: Triple A syndrome; linkage disequilibrium; homozygosity mapping; North Africa; inbreeding; chromosome 12

\section{Introduction}

Triple A syndrome (Allgrovesyndrome, MIM no. 231550) is a rare autosomal recessive disorder characterised by ACTH-

\section{Correspondence: S Lyonnet, Unité INSERM U-393, Hôpital} Necker-Enfants Malades, 149, rue de Sèvres, 75743 Paris Cedex 15, France. Tel: +33 1444951 36; Fax: +33 1444951 50;

E-mail: lyonnet@necker.fr

Received 24 December 1999; revised 21 March 2000; accepted 5 April 2000 resistant adrenal insufficiency, achalasia of the cardia, and alacrimia. ${ }^{1-4}$ Whilst triple A syndrome is usually expressed during the first decade of life with severe hypoglycemic episodes, late onset with progressive neurological symptoms such as autonomic and peripheral neuropathies, dementia, and cerebellar ataxia has been reported. ${ }^{5-7}$ Both the progressive neurologic features and the parasympathic innervation of most involved organs suggested mutation of a gene encoding either a neuromodulator or a neurotrophic factor. 
In particular, based on overlaps between triple A syndrome and familial glucocorticoid deficiency, the ACTH receptor and the vasoactive intestinal peptide genes have been excluded as candidate genes. ${ }^{8}$ Systematic linkage screening in triple A syndrome families showed linkage of the disease locus to chromosome 12 q13 in a maximum genetic interval spanning $6 \mathrm{cM}$ between the D12S1629 and D12S312 loci. ${ }^{9}$ However, no candidate gene was thought to lie in this region whose genetic length was not amenable to positional cloning. Using the combination of homozygosity mapping and linkage disequilibrium in a highly inbred North African families, we localised the triple $A$ locus to a $0 \mathrm{cM}$ interval at the D12S1604 locus and confirmed genetic homogeneity of this condition. We subsequently developed a YAC/PAC contig encompassing the triple $A$ minimal region that was mapped to a $1.7 \mathrm{Mb}$ DNA fragment accessible to gene cloning.

\section{Patients and methods Families}

Inclusion criteria for triple A syndrome families were the presence of all the following:

(i) laboratory proven glucocorticoid deficiency,

(ii) alacrimia with positive Schirmer test, and

(iii) achalasia of the cardia with positive manometry or barium study in at least one family member.

A total of 12 families including 7 multiplex kindreds were studied and blood samples were collected from 22 patients and 45 relatives, with informed consent. Seven families originated from North Africa: Algeria (five families) and Tunisia (two families, Figure 1). Family M 6 was split into two kindreds: M6a with consanguineous and M6b with nonconsanguineous parents. The other families originated from France (family 8), Spain (family 9), Croatia (families 10-11), and Turkey (family 12, Figure 1).

\section{Genotyping}

Genomic DNA was extracted according to standard procedures. Linkage studies were performed using ten contiguous microsatellite DNA markers mapping to the $12 q 13$ region and spanning a $3.9 \mathrm{cM}$ interval (sex average distance) in the following order: tel /D12S312 - D12S103 - D12S325 D12S1586 - D12S1651 - D12S1604 - D12S1618 - D12S359 D12S96 - D12S368/ cen. ${ }^{10}$ Marker informativity varied from 61 to $83 \%$. PCR amplification of the microsatellite markers was carried out with 100 ng genomic DNA in a $25-\mu$ l total reaction volume containing: $0.2 \mathrm{U}$ of Taq polymerase (Life Technologies, Paris, France), $1 \mu \mathrm{m}$ each of the forward and reverse primer, $200 \mu \mathrm{m}$ dNTPs, and $1 \times$ reaction buffer $(50$ $\mathrm{mm} \mathrm{KCl}, 20 \mathrm{~mm}$ Tris- $\mathrm{HCl}$ pH 8.4, 2 mm MgCl2). Amplification was performed under the following conditions: $94^{\circ} \mathrm{C}$ for 5 min, followed by 30 cycles at $94^{\circ} \mathrm{C}$ for $30 \mathrm{~s}, 55^{\circ} \mathrm{C}$ for $30 \mathrm{~s}$, and $72^{\circ} \mathrm{C}$ for $30 \mathrm{~s}$, with a final 5 min extension at $72^{\circ} \mathrm{C}$. PCR products were mixed with formamide-loading buffer and were loaded on to a $6 \%$ denaturing acrylamide gel. Electrophoresis was performed at $70 \mathrm{~W}$ for 1-3 h. Gels were blotted on to nylon membranes (Appligene, Illkirch, France), labelled by chemiluminescence according to the manufacturer's instructions (ECL, Amersham, Buckinghamshire, UK), and exposed to X-ray film for $10 \mathrm{~min}^{11}$

\section{Statistical analyses}

Linkage of the triple A locus was tested assuming that the disease is inherited as an autosomal recessive trait with full penetrance (normal allele frequency $f=0.999$ ). Two-point lod scores were calculated for linkage between the triple $A$ locus and each of the microsatellite DNA markers using the Linkage Package (Version 5.1, M-LINK program). Allele frequencies were compared between mutant $(n=16)$ and normal chromosomes $(n=14)$ in nuclear families. We also compared the allele frequencies at the D12S1604 locus between mutant chromosomes and 88 control chromosomes from 44 unrelated and unselected North African individuals. Significance of linkage disequilibrium was tested using the standard $\chi_{2}$ test. An attempt was made to estimate the age of the triple $A$ mutation from linkage disequilibrium of flanking markers. The mutation occurred on an ancestor haplotype that could be reconstructed by comparing the distinct family haplotypes. The number of generations that had elapsed since the appearance of the triple A mutation in the North African population (ie the earliest common ancestor) was estimated. $^{12}$

\section{YAC and PAC screening}

For physical mapping of the triple A locus, 5 YACs, of the 12q13 region were first identified (CEPH-Généthon database, $\left.{ }^{13}\right)$, namely YACs $813 \mathrm{~h} 5$ (600 kb), $975 f 5$ (270 kb), 928a12 (1330 kb), $790 f 7(570 \mathrm{~kb})$, and $903 \mathrm{fl}$ (length unknown). The ten polymorphic markers mapping to the critical region between loci D12S368 and D12S312 were ordered on the overlapping YACS contig by PCR amplification.

PACs from the Genome System Library ${ }^{\circledR}$ (St Louis, MI, USA) were screened with the AFMal89yd9 probe at the D12S1604 locus. The presence of polymorphic DNA markers was established by PCR amplification on PAC DNA isolated as previously described. ${ }^{14}$ The length of YAC and PACs was evaluated by field inversion gel electrophoresis (FIGE Mapper, Biorad, Richmond, CA, USA) under the following conditions: forward $180 \mathrm{~V}$, reverse $120 \mathrm{~V}$, with a $0.1-2 \mathrm{~s}$ switch time for $16 \mathrm{~h}$ at $20^{\circ} \mathrm{C} .{ }^{15}$

\section{Physical mapping of the neurokinin B gene}

The neurokinin B gene has been mapped to the $12 q 13$ region and could be regarded as an interesting candidate gene for triple A syndrome. ${ }^{16,17}$ The presence of the neurokinin B gene 

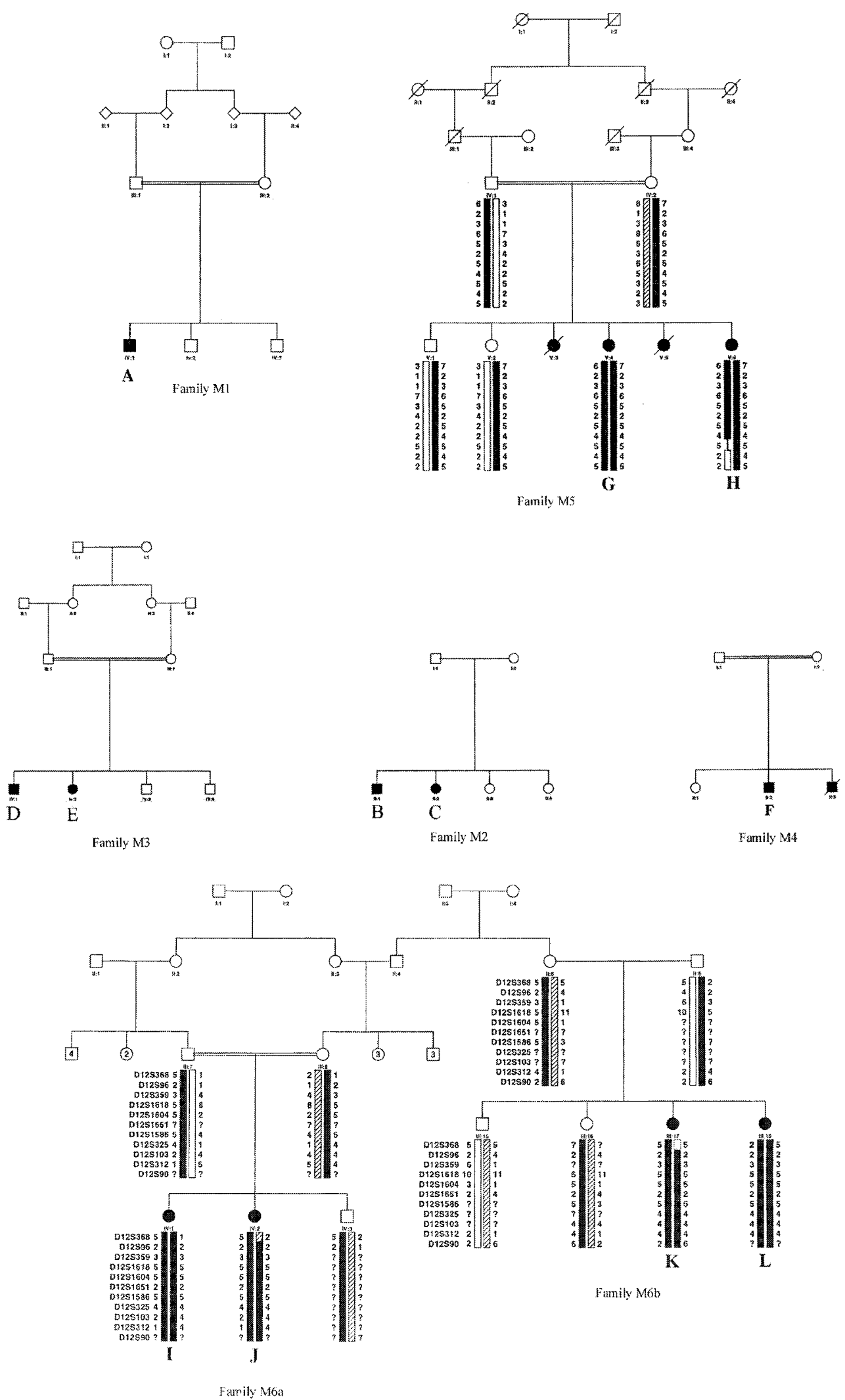

Figure 1 Continued overleaf 
616
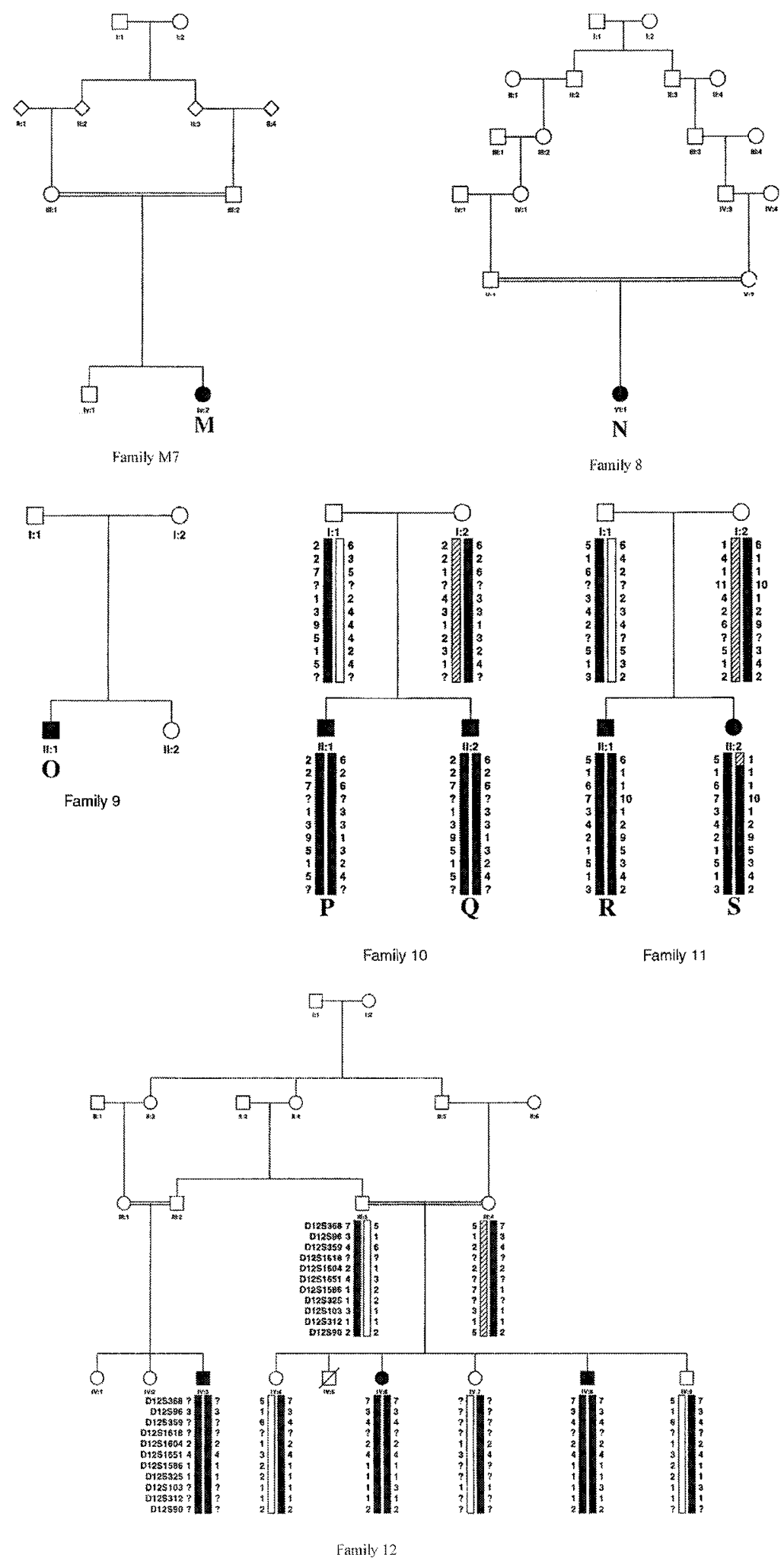

Figure 1 Triple A syndrome pedigrees. The polymorphic DNA haplotypes are presented with mutant (solid columns) and normal (open and hatched columns) chromosomes for families with obligate recombinants (families M5, M6a and b) and the three families whose genotypes are not shown in Table 1. 
in the triple A PAC/YAC contig was tested by PCR amplification using oligonucleotide primers for exons 2-5 (primers available on request).

\section{Results \\ Genotyping}

Two-point lod scores between the triple A locus and 12q13 polymorphic markers in 12 triple A families are shown in Table 1. The maximum lod score was obtained for marker AFMa189yd 9 at the D12S1604 locus ( $Z=10.89$ at $\Theta=0 \%)$, indicating that this marker was completely linked to the disease in the families studied. Haplotype analyses allowed characterisation of a total of four obligate recombination events in four families. The recombinant mutant chromosomes in affected individuals) and K (families M 6a and M 6b, Figure 1 ), and $S$ (family 11 , Figure 1 ) placed the proximal boundary of the triple A region at the D12S368 locus (Table 1; Figure 1). A recombination event in patient $\mathrm{H}$ (family $\mathrm{M} 5$, Figure 1) suggested that the distal boundary was at the D12S312 locus (Table 1; Figure 1). Thus, based on meiotic recombinant mapping, the triple $A$ syndrome locus was refined to a genetic interval of $3.9 \mathrm{cM}$ between loci D12S368 and D12S312.

Moreover, homozygosity was observed for each of the markers between the D12S368 and D12S312 loci in each of the 13 affected individuals in the seven consanguineous families studied (M 1, M3 to M5, M6a, M 7, 8 and 12; Figure 1 and Table 1). However, the two patients of the M6a family showed heterozygosity at locus D12S103 (Figure 1, Table 1), supporting the hypothesis that the telomeric boundary was distal to the D12S325 locus (the genetic distance between D12S103 and D12S325 is unknown).

Comparison of mutant chromosomes in families originating from North Africa suggested a common ancestral mutant haplotype. Indeed, Table 1 shows that 10 patients of North African origin had homozygosity for a single allele at each of the contiguous polymorphic loci allowing definition of a common mutant haplotype, namely: 5 (D12S1604)-2 (D12S1651)-5 (D12S1586)-4 (D12S325). In agreement with this, patients $B$ and $C$ in non-consanguineous family $M 2$ (Figure 1) harboured this haplotype on their maternal mutant chromosome only. The mutant haplotype was restricted to the $\mathrm{D} 12 \mathrm{S1604}$ locus when affected individuals of M1 and M2 were included (Figure 1). Therefore all patients originating from North Africa showed homozygosity for a unique allele at the D12S1604 locus (allele 5), suggesting a founder effect for a mutant triple $A$ gene in families of North African origin (M 1 to $M 7$ ). In order to test this hypothesis, we estimated the frequency of polymorphic alleles both in normal chromosomes $(\mathrm{n}=14)$ and in a series of 88 chromosomes from unrelated controls of the same ethnic background (Table 2). The distribution of alleles 5, 2, 5, and 4 at loci D12S1604, D12S1651, D12S1586 and D12S325

Table 1 Polymorphic DNA haplotypes of mutant chromosomes in North African (M1 to M7), French (8) and Spain (9) triple A families

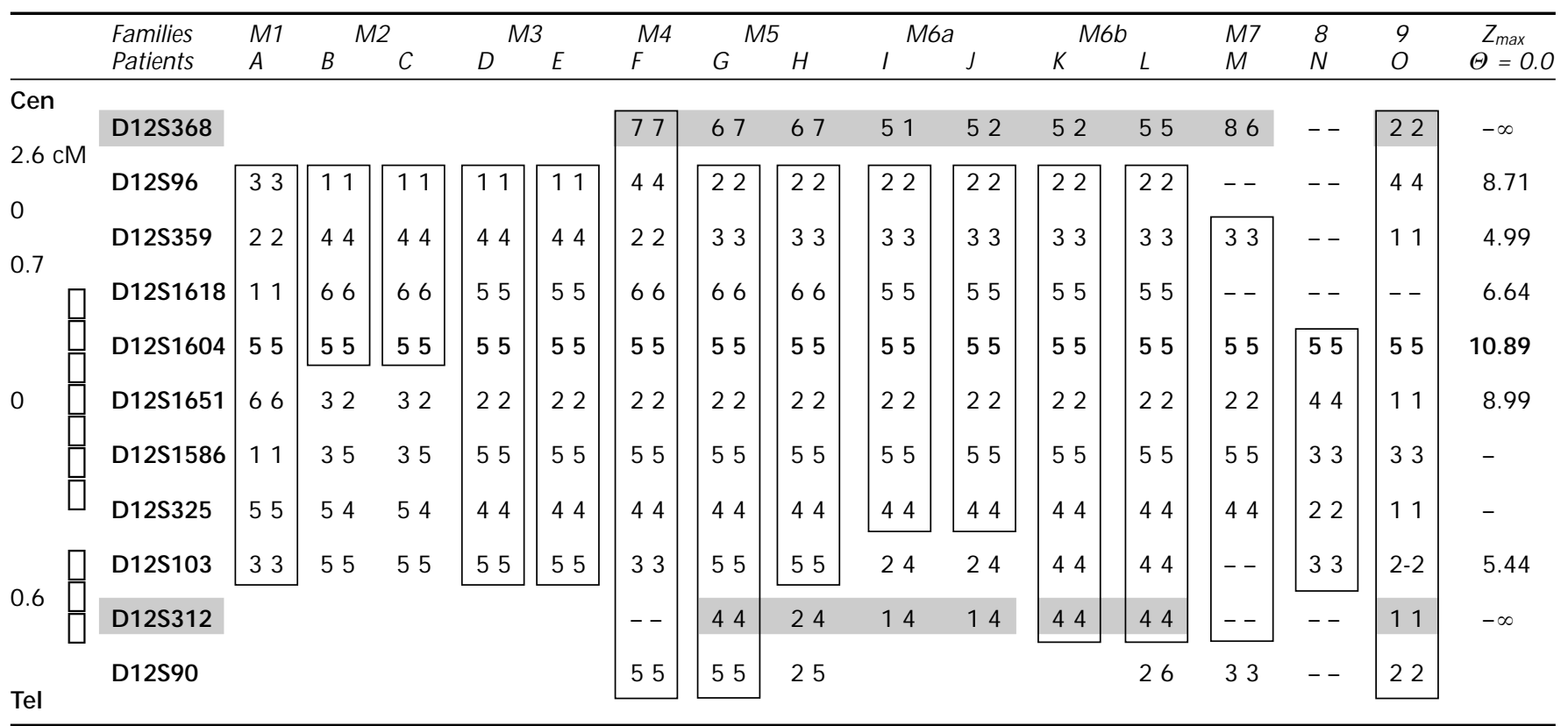

Maximum two-point lod scores between chromosome 12q13 polymorphic DNA loci and the triple A locus are shown in the right-hand column (recombination fractions between markers are indicated in CM in the left-hand column). Tints indicate obligatory recombination events; solid outline boxes indicate homozygosity in patients (families M2, M6b and M9 are non-consanguineous); bold values indicate full linkage disequilibrium with allele 5 at the D12S1604 locus. 

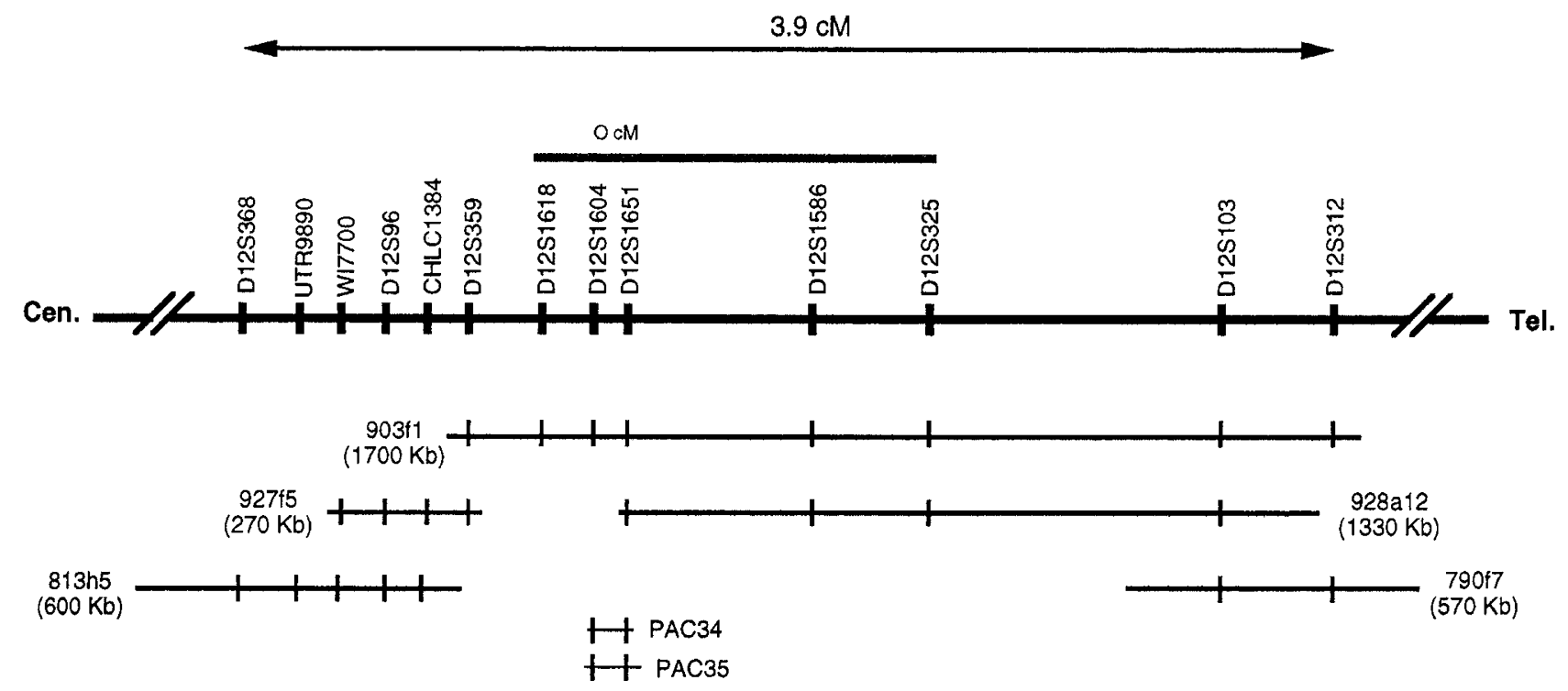

$100 \mathrm{~Kb}$

Figure 2 Physical map (YAC/ PAC contig) of chromosome 12q13. Polymorphic loci in complete (D12S1604) or partial (D12S1651, D12S1586, D12S325, D12S103) linkage disequilibrium with the triple A locus are indicated. STS positions are indicated. The physical distance between polymorphic loci D12S1651 and D12S103 is unknown.

Table 2 Allele frequencies at chromosome 12q13 polymorphic loci in the North African population

\begin{tabular}{lcccc}
\hline Locus & D12S1604 & D12S1651 & D12S1586 & D12S325 \\
Marker & AFM a189yd9 & AFM b069we9 & AFM a110xgl & AFM 234tf12 \\
\hline $\begin{array}{l}\text { Allele } \\
\begin{array}{l}\text { Mutant chromosomes } \\
(n=16)\end{array}\end{array}$ & 5 & 2 & 5 & 4 \\
$\begin{array}{l}\text { Normal chromosomes } \\
(n=14)\end{array}$ & $16(100 \%)$ & $12(75 \%)$ & $12(75 \%)$ & $12(75 \%)$ \\
$\begin{array}{l}\text { Control chromosomes } \\
(n=88)\end{array}$ & $2(14.3 \%)$ & 0 & $1(7.15 \%)$ & 0 \\
\end{tabular}

Frequencies are indicated for mutant chromosomes, and for normal chromosomes originating from the parents of affected individuals, as well as from 44 unrelated individuals with the same ethnic background (control chromosomes).

respectively was significantly different in affected North African individuals compared with normal chromosomes in both their parents and unrelated North African controls (Table 2). In particular, allele 5 at the D12S1604 locus displayed strong linkage disequilibrium with the triple $A$ mutant allele (100\% in mutant chromosomes vs $9.1 \%$ in control North African chromosomes, P < 0.001). Moreover, homozygosity for allele 5 at the D12S1604 locus was observed in patients $\mathrm{N}$ and $\mathrm{O}$ from French and Spanish families (Families 8 and 9, respectively, Figure 1), suggesting that the linkage disequilibrium between the $\mathrm{D} 12 \mathrm{~S} 1604$ and the triple A loci, and hence the founder effect, might extend to other M editerranean countries (frequency of allele 5 in the French population: $12 \%)$.

\section{Physical mapping and neurokinin gene exclusion}

The entire genetic interval encompassing the triple A locus lies in a three YAC contig spanning $2.4 \mathrm{Mb}(813 \mathrm{~h} 5,927 \mathrm{f5}$, 903f1; Figure 2). The region with full linkage disequilibrium mapped to the $903 f 1$ YAC whose size was $1700 \mathrm{~kb}$. To refine this physical interval, two PACs (PAC 34 and 35) were obtained from the Genome System Library ${ }^{\circledR}$ screened with the AFM a189yd9 probe at the D12S1604 locus. Interestingly, marker AFM b069we9 at the D12S1651 locus, which was in partial linkage disequilibrium (12/16 chromosomes), was also present on both PACs. The size of PAC 34 was $66 \mathrm{~kb}$ (not shown). This result suggests that PAC 34 encompasses at least one extremity of the triple A gene. The neurokinin $B$ gene was excluded from the candidate region since no PCR signal could be obtained with any of the four exons tested using PACs 34 and 35 and the YAC contig (not shown). 


\section{Discussion}

Triple A syndrome (Allgrove syndrome) is a highly heterogeneous autosomal recessive disorder with high lethality. ${ }^{1}$ The triple A gene has been previously mapped to chromosome 12 q13 in a 6 cM interval between loci D12S1629 and D12S312. ${ }^{9,18}$ In order to refine this interval, we have extended linkage analysis to 12 triple A families using additional polymorphic DNA markers chosen in the vicinity of the triple A gene locus. By genotyping 22 affected individuals and their 45 relatives, we confirmed that the triple $A$ gene maps to the $12 q 13$ region and suggest that triple A is probably a genetically homogeneous disorder in patients of North African ancestry. Using conventional recombinational mapping, we were able to narrow the triple $A$ region to a $3.9 \mathrm{cM}$ interval flanked by marker loci D12S368 and D12S312. Then, homozygosity mapping allowed us to place the telomeric boundary proximal to D12S103. However, only linkage disequilibrium allowed us to make an accurate genetic refinement of the triple A locus. Indeed, linkage disequilibrium could be regarded as the most powerful tool in genetic mapping for positional cloning of disease genes. ${ }^{19}$ Linkage disequilibrium mapping takes advantage of ancestral recombinational events that have occurred during the history of a population. ${ }^{20,21}$ Since most of the disease chromosomes in an inbred small population carry a single mutation, the smaller the region with linkage disequilibrium, the older the mutation. In fact, a strong linkage disequilibrium was detected between the triple $A$ locus and several polymorphic DNA markers loci in all North African kindreds tested. In particular, total linkage disequilibrium was found at the D12S1604 locus (16/16). This finding supports the hypothesis of a unique mutation resulting in triple $A$ syndrome in North Africa. Conversely, only partial disequilibrium (12/16) was found at loci that are either telomeric to D12S1604 (D12S1651, D12S1586, D12S325, D12S103) or centromeric to D12S1618 (6/16). Interestingly, these five contiguous polymorphic markers map within a $0 \mathrm{cM}$ gen etic interval. Further evidence regarding the local isation of the triple $A$ gene was obtained by constructing haplotypes for the polymorphic markers in the critical region. Analysis of markers at loci D12S1604, D12S1651, D12S1586, and D12S325 showed that most of the mutant triple A chromosomes may be derived from a single founder chromosome carrying the 5-2-5-4 haplotype, which was reduced to only one marker at locus D12S1604 in all North African triple A families.

Both the geographical distribution of carriers of the mutation (Algeria and Tunisia) and the size of the common ancestral haplotype, indicate that the triple A mutation in the North African population is very old. Our data suggest that the founder mutation for the triple A mutation occurred in the Arabian population a long time before the migration for the triple A mutation to North Africa. Computation suggested that the most likely number of generations that have elapsed since the appearance of the mutation is 100-110. Assuming that a generation is equivalent to 24 years, ${ }^{12,22}$ this would indicate that the triple A mutation is at least 2400 years old (not shown). Moreover, since linkage disequilibrium at D12S1604 was al so present in two patients from Southern Europe (France and Spain), the founder effect might well extend to other Mediterranean countries.

Inter- and intra-familial clinical heterogeneity of triple A syndrome supports the existence of allelic variation at a single locus or of modifier genes, rather than genetic heterogeneity. ${ }^{2}$ Interestingly, both the full blown (MIM no. 231550) and partial (achalasia-alacrimia, MIM no. 200440) triple $A$ phenotypes co-segregate in single large triple $A$ kindreds such as family M 6 in our series (Figure 1), suggesting gen etic homogen eity for these two conditions that have been separated in the MIM catalogue.

Both genetic homogeneity and fine genetic mapping now allow prenatal diagnosis of the triple A syndrome to be proposed based on indirect genetic analysis. In addition, since all our North African families exhibited linkage disequilibrium, homozygosity for allele 5 at the D12S1604 locus may help in diagnosing triple A syndrome in North African patients, since the syndrome is still very difficult to prove based on clinical and laboratory criteria alone.

Finally, physical mapping allowed us to map the triple A gene to a 1.7 Mb YAC (YAC 903f1). This YAC contains the tel omeric recombinant boundary of obligate recombinants as well as each of the four loci in strong linkage disequilibrium with the tripleA locus. The YAC al so contains both D12S1604 and D12S1651 loci that span the $0 \mathrm{cM}$ interval in a $66 \mathrm{~kb}$ PAC (PAC 34). Since D12S1604 and D12S1651 show, respectively, a complete and partial linkage disequilibrium, it is thus likely that the triple A gene may be completely or partially contained in the PAC 34. For these reasons we are currently carrying out DNA sequencing and EST identification as a first step towards cloning the triple A gene.

\section{Acknowledgements}

We thank J-C Carel, P-F Bougnières, C Dupont (Saint-Vincent-de-Paul, Paris), C Ponte, J Weill (Lille), M Begeot (Lyon), J-M Garnier, G Pinto, R Rappaport, J-M Rozet (Necker-Enfants Malades, Paris), M Dumić (Zagreb), D Rieu (Montpellier), Y Lebouc (Trousseau, Paris) for helpful discussions. This work was supported by grants from the AFM and the Assistance Publique-Hôpitaux de Paris. $\mathrm{SH}-\mathrm{R}, \mathrm{RS}$ and $\mathrm{AP}$ contributed equally to this work.

Electronic Database Information Online Mendelian Inheritance in Man (OMIM), http://www.ncbi.nlm.nih.gov/ Omim (for Triple A syndrome MIM no. 231550, Achalasia-Alacrimia no. 200440, Neurokinin B gene MIM no. 162330)

Généthon, http://www.genethon.fr (for markers)

Center for Medical Genetics, Marshfield Medical Research Foundation, http://www.marshmed.org/genetics (for genetic interval and markers position)

CEPH-Généthon database, http://www.cephb.frcephdb/ (for YAC contig and STS position)

Genatlas, http://bisance.citi2.fr (for neurokinin B gene) 


\section{References}

1 Allgrove J, Clayden GS, Grant DB, Macaulay JC: Familial glucocorticoid deficiency with achalasia of the cardia and deficient tear production. Lancet 1978; 1: 1284-1286.

2 Moore PS, Couch RM, Perry YS, Shuckett EP, Winter JS: Allgrove syndrome: an autosomal recessive syndrome of ACTH insensitivity, achalasia and alacrimia. Clin Endocrinol (Oxford) 1991; 34: 107-114.

3 Grant DB, Dunger DB, Smith I, Hyland K: Familial glucocorticoid deficiency with achalasia of the cardia, associated with mixed neuropathy, long-tract degeneration and mild dementia. Eur J Pediatr 1992; 151: 85-89.

4 Heinrichs C, Tsigos C, Deschepper J et al: Familial adrenocorticotropin unresponsiveness associated with alacrimia and achalasia: biochemical and molecular studies in two siblings with clinical heterogeneity. Eur J Pediatr 1995; 154: 191-196.

5 Ehrich E, Aranoff G, Johnson WG: Familial achalasia associated with adrenocortical insufficiency, alacrimia and neurological abnormalities. Am J Med Genet 1987; 26: 637-644.

6 Gazarian M, Cowell CT, Bonney M, Grigor WG: The '4-A' syndrome: adrenocortical insufficiency associated with achalasia, alacrimia, autonomic and other neurological abnormalities. Eur J Pediatr 1995; 154: 18-23.

7 Chu ML, Berlin D, Axelrod FB: Allgrove syndrome: documenting cholinergic dysfunction by autonomic tests. J Pediat 1996; 129: 156-159.

8 Weber A, Farrall M, Dean HJ, Clark AJL: Exclusion of the ACTH receptor and vasoactive intestinal peptide loci as candidate genes for the triple A syndrome. Horm Res 1995; 44 (Suppl 1): 5.

9 Weber $A$, Wienker TF, Jung $M$ et al: Linkage of the gene for the triple A syndrome to chromosome 12q13 near the type II keratin gene cluster. Hum M ol Genet 1996; 5: 2061-2066.

10 Dib C, Faure S, Fizames C et al: A comprehensive genetic map of the human genome based on 5,264 microsatellites. Nature 1996; 380: 152-154.
11 Belin V, Cusin V et al: SHOX mutations in dyschondrosteosis (Leri-Weill syndrome). Nat Genet 1998; 19: 67-69.

12 Piccolo $F$, Jean pierre $M$, Leturcq $F$ et al: A founder mutation in the $\gamma$-sarcoglycan gene of Gypsies possibly predating their migration out of India. Hum Mol Genet 1996; 5: 2019-2022.

13 Chumakov IM, Rigault P, Le Gall I et al: A YAC contig map of the human genome. Nature 1995; 377: 175-297.

14 Cole SE, Reeves RH: A cluster of keratin-associated proteins on mouse chromosomes 10 in the region of conserved linkage with human chromosome 21. Genomics 1998; 54: 437-442.

15 Konrad M, Saunier S, Heidet L et al: Large homozygous deletions of the 2q13 region are a major cause of juvenile nephronophtisis. Hum Mol Genet 1996; 5: 367-371.

16 Munekata E: Neurokinin A and B. Comp Biochem Physiol C 1991; 98: 171-179.

17 Malendowicz LK: Role of neuromedins in the regulation of adrenocortical function. Horm Metab Res 1998; 30: 374-383.

18 Stratakis CA, Lin JP, Pras E, Rennert OM, Bourdony CJ, Chan WY: Segregation of Allgrove (TripleA) syndrome in Puerto Rican kindreds with chromosome 12 (12q13) polymorphic markers. Proc Assoc Am Physicians 1997; 109: 478-482.

19 Jorde LB: Linkage disequilibrium as a gene-mapping tool. Am J Hum Genet 1995; 56: 11-14.

20 Hastbacka J, de La Chapelle A, Kaitila I, Sistonen P, Weaver A, Lander E: Linkage disequilibrium mapping in isolated founder populations: diastrophic dysplasia in Finland. Nat Genet 1992; 2: 204-211.

21 de la Chapelle A, Wright FA: Linkage disequilibrium mapping in isolated populations: the example of Finland revisited. Proc $\mathrm{N}$ at Acad Sci USA 1998; 95: 12416-12423.

22 Bittles AH, Mason WM, Greene J, Rao NA: Reproductive behavior and health in consanguineous marriages. Science 1991; 252: 789-794. 